\title{
Mutation in ribosomal protein S5 leads to spectinomycin resistance in Neisseria gonorrhoeae
}

\author{
Elena N. Ilina*, Maya V. Malakhova, Ivan N. Bodoev, Nina Y. Oparina, Alla V. Filimonova and \\ Vadim M. Govorun
}

Research Institute of Physico-Chemical Medicine, Moscow, Russia

\author{
Edited by: \\ Kunihiko Nishino, Osaka University, \\ Japan \\ Reviewed by: \\ Lilia Macovei, Harvard Medical \\ School, USA \\ Petr V. Sergiev, Lomonosov Moscow \\ State University, Russia \\ ${ }^{*}$ Correspondence: \\ Elena N. Ilina, Research Institute of \\ Physico-Chemical Medicine, Malaya \\ Pirogovskaya st., 1a, 119435, \\ Moscow, Russia \\ e-mail: ilinaen@gmail.com
}

Spectinomycin remains a useful reserve option for therapy of gonorrhea. The emergence of multidrug-resistant Neisseria gonorrhoeae strains with decreased susceptibility to cefixime and to ceftriaxone makes it the only medicine still effective for treatment of gonorrhea infection in analogous cases. However, adoption of spectinomycin as a routinely used drug of choice was soon followed by reports of spectinomycin resistance. The main molecular mechanism of spectinomycin resistance in N. gonorrhoeae was C1192T substitution in $16 \mathrm{~S}$ rRNA genes. Here we reported a Thr-24 $\rightarrow$ Pro mutation in ribosomal protein S5 (RPS5) found in spectinomycin resistant clinical N. gonorrhoeae strain, which carried no changes in 16S rRNA. In a series of experiments, the transfer of rpsE gene allele encoding the mutant RPS5 to the recipient $N$. gonorrhoeae strains was analyzed. The relatively high rate of transformation [ca. $10^{-5}$ colony-forming units (CFUs)] indicates the possibility of spread of spectinonycin resistance within gonococcal population due to the horizontal gene transfer (HGT).

Keywords: spectinomycin resistance, spot-transformation, horizontal gene transfer, ribosomal proteins, mutations

\section{INTRODUCTION}

Neisseria gonorrhoeae is an obligate pathogen causing gonorrhea, one of the most abundant sexually transmitted diseases. The expansion of drug resistant N. gonorrhoeae strains is one of the global contemporary problems. The emergence and spreading of multidrug resistant (MDR) strains, which are resistant to penicillin, tetracycline, and ciprofloxacin, are reported throughout the world. In some countries, including Russia, about $50 \%$ of clinical $N$. gonorrhoeae strains identified as MDR (Kubanova et al., 2010; Allen et al., 2011). Until recently, all these strains remain susceptible to spectinomycin and to extendedspectrum cephalosporins (ceftriaxone and cefixime). Recently, $N$. gonorrhoeae strains displayed reduced susceptibility to the extended-spectrum cephalosporins. Moreover, several cases of clinical failures during the cefixime treatment have been reported (Wang et al., 2003; Heymans et al., 2012; Unemo et al., 2012). The spectinomycin remains the only antibiotic still effective in analogous cases. However, adoption of spectinomycin as the routinely used drug of choice was soon followed by reports of spectinomycin resistance (Boslego et al., 1987). The treatment of gonorrhea infection caused by extremely drug resistant (XDR) $N$. gonorrhoeae strains is very difficult, and the extended knowledge of molecular mechanisms of drug resistance is required for development of new tests needed to for routine diagnose in clinical practice.

In general, these are several mechanisms occurring in the bacteria which confer them antibiotic resistance. The most common are known to be drug inactivation, efflux-pumping of the drug out of the cell, and target modification due to single nucleotide change polymorphisms (SNPs) mainly (Davies and Davies, 2010). A bacterial strain can acquire resistance either by mutation of its own genes or by the uptake of exogenous genes by horizontal transfer from other microbes. Within bacterial population horizontal gene transfer (HGT) occurs via conjugation, transformation and transduction. With regards to neisseria genus these bacteria are naturally transformable and are capable to exchange their genetic material with high frequency (Koomey, 1998). This property leads to the rapid dissemination of antibiotic resistance markers and to the panmictic structure of the gonococcal and meningococcal populations.

Spectinomycin belongs to an aminocyclitol antibiotic class which blocks biosynthesis of bacterial proteins. After entering the bacterial cells, spectinomycin binds a ribosome beneath the 34 helix of $16 \mathrm{~S}$ rRNA and interrupts elongation of the polypeptide during protein synthesis apparently preventing the translocation of the peptidyl tRNA from the A-site to the P-site (Carter et al., 2000; Borovinskaya et al., 2007).

Various bacteria demonstrate spectinomycin resistance, which results from three different mechanisms. The most frequent mechanism is the drug inactivation by adenylylation. Until now a diverse number of adenyltransferases, which exhibit the spectinomycin resistant (Spt-R) phenotype, was described (Shaw et al., 1993). One group of enzymes referred as $\operatorname{AAD}\left(3^{\prime \prime}\right)(9)$ [or ANT $\left.\left(3^{\prime \prime}\right)(9)\right]$ confers combined resistance to spectinomycin and streptomycin. These enzymes were found in a variety of gramnegative bacteria (Yamada et al., 1968; Hollingshead and Vapnek, 1985; Kehrenberg et al., 2005) and also in gram-positive bacteria (Clark et al., 1999). The other group of adenyltransferase referred as $\mathrm{AAD}(9)$ [or $\mathrm{ANT}(9)$ ] confers the Spt-R phenotype only (LeBlanc et al., 1991).

On the other hand, the spectinomycin resistance can result from alteration of $30 \mathrm{~S}$ subunit of bacterial ribosome due to 
mutations in chromosomal genes encoding ribosomal RNAs or proteins. Thus, mutations in the spectinomycin binding region of helix 34 of $16 \mathrm{~S}$ rRNA encompassing the cross-linked positions from 1063 to 1066 and from 1190 to 1193 (in Escherichia coli numbering) lead to high level resistance to spectinomycin (Sigmund et al., 1984; Brink et al., 1994). These mutations were discovered for various bacteria such as Chlamydia psittaci, Borrelia burgdorferi, E. coli, Pasteurella multocida (Johanson and Hughes, 1995; Binet and Maurelli, 2005; Criswell et al., 2006; Kehrenberg and Schwarz, 2007) including N. gonorrhoeae and N. meningitidis (Maness et al., 1974; Galimand et al., 2000). Although ribosomal protein S5 (RPS5) is not involved in spectinomycin binding, it is located very close to the antibiotic binding site (within $5 \mathrm{~A}^{\circ}$ ) (Wirmer and Westhof, 2006). Accordingly, it has been found that mutations in RPS5 can lead to spectinomycin resistance in E. coli (Funatsu et al., 1972; Bilgin et al., 1990) and in P. multocida (Kehrenberg and Schwarz, 2007).

Until recently, the only $16 \mathrm{~S}$ rRNA substitutions were found in Spt-R bacteria from Neisseria genus (Maness et al., 1974; Galimand et al., 2000). In this study, we reported the discovery of isolated mutation in RPS5 in Spt-R clinical N. gonorrhoeae strain, confirmed by Unemo et al. (2013), and estimate the potential of Spt-R horizontal spread. We established that the $10^{-5}$ colony-forming units (CFU) from transformation experiments represents a high risk of spectinomycin resistance spread within gonococcal population.

\section{MATERIALS AND METHODS \\ BACTERIAL STRAINS}

N. gonorrhoeae clinical isolates were collected as a part of previous study (Ilina et al., 2008) and stored at a temperature of $-80^{\circ} \mathrm{C}$. The studied N. gonorrhoeae clinical isolates and strains are shown in Table 1.
For any manipulations, gonococci were cultivated on the $\mathrm{BBL}^{\mathrm{TM}} \mathrm{GC}$ agar base (Becton Dickinson \& Co, USA) supplemented with $1 \% \mathrm{BBL}^{\mathrm{TM}}$ IsoVitaleX ${ }^{\mathrm{TM}}$ Enrichment (Becton Dickinson \& Co, USA) at $37^{\circ} \mathrm{C}$ in a humid atmosphere with $5 \%$ $\mathrm{CO}_{2}$ during 20-24h.

\section{PHENOTYPIC CHARACTERIZATION}

Susceptibility testing to penicillin G, tetracycline, ciprofloxacin, spectinomycin and ceftriaxone was performed by agar dilution method in accordance with CLSI recommendations (CLSI document M100-S17, 2007). All antibiotics were manufactured by Sigma, USA. N. gonorrhoeae strain ATCC 49226 was used as a control.

\section{GONOCOCCAL TRANSFORMATION}

Spot-transformation of gonococci was performed as described (Dillard, 2011). Briefly, $200 \mathrm{ng}$ of amplified DNA fragments in a $10 \mu \mathrm{l}$ volume were placed into spots (diameter approximately $1.5 \mathrm{~cm})$ on a pre-warmed $\left(37^{\circ} \mathrm{C}\right) \mathrm{GC}$ base agar plate. The spot was allowed to soak into the plate. Then piliated colonies of $N$. gonorrhoeae recipient strains were streaked across the plate through the DNA spots. After overnight incubation at $37^{\circ} \mathrm{C}$ in a humid atmosphere with $5 \% \mathrm{CO}_{2}$, colonies were swabbed from the spot with a Dacron swab and re-suspended in $100 \mu \mathrm{l}$ of storage medium $\left(50 \% \mathrm{BBL}^{\mathrm{TM}}\right.$ Brain Heart Infusion, Becton Dickinson \& Co, USA, 30\% Fetal Bovine Serum, Gibco, USA, 20\% glycerin, Sigma, USA). This suspension of cells was then diluted and plated on both GC base agar alone, and GC base agar supplemented with $64 \mathrm{mg} / \mathrm{L}$ of spectinomycin. These plates were incubated at $37^{\circ} \mathrm{C}$ in a humid atmosphere with $5 \% \mathrm{CO}_{2}$ for one to two days, and individual transformants were picked up from spectinomycin supplemented plate. Selected colonies were cultivated once again on spectinomycin supplemented plates; the obtained

Table 1 | Characteristics of gonococci involved into current investigation.

\begin{tabular}{|c|c|c|c|c|c|c|c|c|}
\hline Name & Description & \multicolumn{5}{|c|}{ MICs (mg/L) for } & Serotype & $\begin{array}{l}\text { NG-MAST } \\
\text { sequence type }\end{array}$ \\
\hline NG3 & $\begin{array}{l}\text { Clinical strain derived } \\
\text { from e03.04 isolate }\end{array}$ & $0.015-0.03$ & $0.03-0.06$ & $0.001-0.002$ & $4-8$ & $0.0005-0.001$ & P1B3 & 5187 \\
\hline NG3.2 & $\begin{array}{l}\text { Clinical strain derived } \\
\text { from e03.04 isolate }\end{array}$ & $0.03-0.06$ & $0.03-0.06$ & $0.0005-0.001$ & $64-128$ & $0.001-0.002$ & P1B3 & 5187 \\
\hline NG7 & $\begin{array}{l}\text { Clinical strain, using as a } \\
\text { recipient for } \\
\text { spot-transformation }\end{array}$ & $0.12-0.25$ & 0.015 & 0.001 & $16-32$ & 0.002 & P1B3 & 8633 \\
\hline
\end{tabular}

PEN, penicillin; TET, tetracycline; CIP, ciprofloxacin; SPT, spectinomycin; CRO, ceftriaxone. 
$N$. gonorrhoeae strains were stored at $-80^{\circ} \mathrm{C}$. Transformation frequency was calculated as the number of spectinomycin-resistant colony-forming units $\left(\mathrm{SPT}^{\mathrm{r}} \mathrm{CFU} / \mathrm{ml}\right)$ per total $\mathrm{CFU}(\mathrm{CFU} / \mathrm{ml})$.

\section{GENOTYPIC CHARACTERIZATION USES FEW METHODS: PCR AND SEOUENCING AND MALDI-TOF MS}

Total genomic DNA from tested N. gonorrhoeae strains was isolated by "DNA express" kit (Lytech Ltd, Russia). When necessary, the prepared DNA samples were stored at a temperature of $-20^{\circ} \mathrm{C}$.

Conventional PCR was done using the genomic DNA as a template and oligonucleotide primers described in Table 2. All primers were newly designed using the Oligo_6.31 software (Molecular Biology Insights Inc., USA) and sequences of $N$. gonorrhoeae strain FA1090 (GenBank accession number is NC_002946). Amplification was carried out in $10 \mu \mathrm{l}$ of $66 \mathrm{mM}$ Tris-HCl pH 9.0; $16.6 \mathrm{mM}\left(\mathrm{NH}_{4}\right)_{2} \mathrm{SO}_{4} ; 2.5 \mathrm{mM} \mathrm{MgCl}_{2} ; 0.2 \mathrm{mM}$ of each dNTP; 5 pmol of each primer (Table 2) and 1 unit of TaqPolymerase (Fermentas, Lithuania) under the following conditions: $94^{\circ} \mathrm{C}$ for $20 \mathrm{~s}, 60^{\circ} \mathrm{C}$ for $20 \mathrm{~s}$, and $72^{\circ} \mathrm{C}$ for $15 \mathrm{~s}$, in 35 cycles. A programmed thermocycler TETRAD DNA ENGINE (MJ Research Inc.) was used. The amplification products were analyzed by electrophoresis in 2\% agarose gel.

For further sequencing analysis dephosphorylation of the $5^{\prime}$-end phosphate groups of dNTPs and cleavage of primers in the post-amplification reaction mixture was done by incubation with $0.5 \mathrm{U}$ of shrimp alkaline phosphatase and $0.1 \mathrm{U}$ of exonuclease I (both enzymes from Fermentas, Lithuania) for $20 \mathrm{~min}$ at $37^{\circ} \mathrm{C}$, followed with inactivation by heating at $85^{\circ} \mathrm{C}$ for $10 \mathrm{~min}$. Sequence analysis of $16 \mathrm{~S}$ rRNA genes as well as genes cording the ribosomal proteins S5, S4, and S8 was performed with dedicated primers (Table 2) by the modified Sanger method using the ABI Prism ${ }^{\mathrm{TM}}$ BigDye $^{\circledR}$ Terminator v. 3.1 Cycle Sequencing Kit and 3730xl DNA Analyzer (Applied Biosystems, USA) according to the manufacturer's instruction. Analysis of the nucleotide sequences as well as deduced amino acid sequences was done using the Vector NTI Advance v. 9.0 software (Infomarks Incorporation, USA).

N. gonorrhoeae multi-antigen typing (NG-MAST) was performed as originally described (Martin et al., 2004). Sequence types were identified via NG-MAST (http://www.ng-mast.net) websites.

The rapid identification of A70C nucleotide substitution in $r p s E$ gene, leading to Thr-24 $\rightarrow$ Pro amino acid mutation in RPS5, was done by primer extension reaction followed by MALDI ToF mass spectrometry. For this, PCR was performed as mentioned above with primers form Table 2. The dephosphorylation of the 5 -end phosphate groups of dNTPs in the post-amplification reaction mixture was carried out by incubation with $0.5 \mathrm{U}$ of shrimp alkaline phosphatase (Fermentas, Lithuania) for $20 \mathrm{~min}$ at $37^{\circ} \mathrm{C}$, followed by inactivation of the enzyme by heating for $10 \mathrm{~min}$ at $85^{\circ} \mathrm{C}$. After that amplicon was used as template in thermocyclic primer extension reaction, carried out in $20 \mu \mathrm{L}$ of the mixture of $66 \mathrm{mM}$ Tris- $\mathrm{HCl} \mathrm{pH} 9.0 ; 16.6 \mathrm{mM}\left(\mathrm{NH}_{4}\right)_{2} \mathrm{SO}_{4} ; 2.5 \mathrm{mM} \mathrm{MgCl}_{2}$;

Table 2 | List of primers selected for PCR and sequencing of $\boldsymbol{N}$. gonorrhoeae genes encoding 16S rRNAs, and ribosomal proteins S4, S5, and S8.

Genetic characterization of selected $\boldsymbol{N}$. gonorrhoeae strains

\begin{tabular}{|c|c|c|c|c|c|}
\hline \multicolumn{2}{|l|}{ Target } & \multicolumn{2}{|c|}{ Primers for PCR, 5'-3' sequence(amplicon length) } & \multicolumn{2}{|c|}{ Primers for sequencing, $5^{\prime}-3^{\prime}$ sequence } \\
\hline \multicolumn{2}{|c|}{ 1st copy of $16 \mathrm{~S}$ rRNA } & \multicolumn{2}{|c|}{ aaccgatgaccccctgcttg; gaaaaatgcatggcaggccg (2194 bp) } & \multicolumn{2}{|l|}{ aaccgatgaccccctgcttg } \\
\hline \multicolumn{2}{|c|}{ 2nd copy of $16 \mathrm{~S}$ rRNA } & \multicolumn{2}{|c|}{ aaccgatgaccccctgcttg; accgtaaccgaatgcccctg (2409 bp) } & \multicolumn{2}{|c|}{ tgacgtgtgaagccctggtcataa } \\
\hline \multicolumn{2}{|c|}{4 th copy of $16 \mathrm{~S}$ rRNA } & \multicolumn{2}{|c|}{ aaccgatgaccccctgcttg; acgggatcgggaacgaaaac (2432 bp) } & \multicolumn{2}{|c|}{ tcatcggccgccgatattggcaac } \\
\hline \multicolumn{2}{|c|}{ RPS4 (rpsD gene) } & \multicolumn{2}{|c|}{ tattaaaggtccaggtccaggtcg; catggatgacagtaagatacggcg (954 bp) } & \multicolumn{2}{|l|}{ as for PCR } \\
\hline \multicolumn{2}{|c|}{$\begin{array}{l}\text { RPS8 (rpsH gene) } \\
\text { Genomic DNA fragment } \\
\text { for spot transformation }\end{array}$} & \multicolumn{2}{|c|}{$\begin{array}{l}\text { tcaatccattcctcgtaatgcggc; ttacttctacaccagcgggaacc (637 bp) } \\
\text { tcaaagcaactgtaggtcgg; tgcgttctggtgctaaaggc (12931 bp) }\end{array}$} & \multicolumn{2}{|l|}{ as for PCR } \\
\hline \multicolumn{6}{|c|}{ Identification of RPS5 Thr-24 $\rightarrow$ Pro mutant strains } \\
\hline Target & $\begin{array}{l}\text { Primers for PCR, 5'-3' } \\
\text { sequence (amplicon } \\
\text { length) }\end{array}$ & $\begin{array}{l}\text { Primer for primer } \\
\text { extension } \\
\text { (minisequencing) } \\
\text { reaction, 5'-3' } \\
\text { sequence, molecular } \\
\text { weight }\end{array}$ & $\begin{array}{l}\text { Composition of } \\
\text { dNTP and ddNTP } \\
\text { mix }\end{array}$ & $\begin{array}{l}\text { Predicted } \\
\text { molecular weight } \\
\text { of primer extension } \\
\text { reaction products } \\
\text { for wild type }\end{array}$ & $\begin{array}{l}\text { Predicted } \\
\text { molecular weight } \\
\text { of primer extension } \\
\text { reaction products } \\
\text { for mutant type }\end{array}$ \\
\hline $\begin{array}{l}\text { A70C mutation } \\
\text { in rpsE gene }\end{array}$ & $\begin{array}{l}\text { cgtgcacatgcacgatgagattca; } \\
\text { tgagaaggc- } \\
\text { taaagcagcaggtgt } \\
\text { (727 bp) }\end{array}$ & $\begin{array}{l}\text { gacgacctttaactactttgg } \\
(6397 \mathrm{Da})\end{array}$ & $d G, d d T$ & $\begin{array}{l}6685 \mathrm{Da} \\
(\text { primer }+\mathrm{ddT})\end{array}$ & $\begin{array}{l}7014 \mathrm{Da} \\
(\text { primer }+\mathrm{dG}+\mathrm{ddT})\end{array}$ \\
\hline
\end{tabular}

The scheme of identification of A70C mutation in rpsE gene by primer extension reaction followed by mass spectrometry measuring is also presented. 
$0.2 \mathrm{mM}$ of each dGTP and ddTTP, $10 \mathrm{pmol}$ of internal primer (see Table 2) and 2 units of TermiPol DNA Polymerase (Solis Biodyne, Estonia) according to the followed profiling: $94^{\circ} \mathrm{C}$ for $20 \mathrm{~s}, 58^{\circ} \mathrm{C}$ for $20 \mathrm{~s}$, and $72^{\circ} \mathrm{C}$ for $15 \mathrm{~s}$, in 70 cycles.

The products from primer extension reaction were purified using the SpectroCLEAN Kit (Sequenom, USA) according to the manufacturer's instruction.

An aliquote $(0.2-1 \mu \mathrm{L})$ of purified products from primer extension reaction was spotted onto a matrix, which was preliminarily dried on the MALDI target AnchorChip ${ }^{\mathrm{TM}}$ with $400 \mu \mathrm{m}$ diameter of anchor sports (Bruker Daltonics, Germany). The matrix employed was a saturated solution of 3-hydroxypicolinic acid (Fluka, Germany) in a 1:1 acetonitrile/water mixture (Merck, Germany) mixed with $0.4 \mathrm{M}$ dibasic ammonium citrate (Fluka, Germany) in 9:1 vol. ratio. All solvents were of quality suitable for mass spectrometry. Mass spectra were collected on a Microflex LT MALDI ToF mass spectrometer (Bruker Daltonics, Germany) that was operated in the positive linear mode. A $337 \mathrm{~nm}$ nitrogen laser with the $9 \mathrm{~Hz}$ pulse frequency was used. Mass spectrometer parameters were optimized for the range of $\mathrm{m} / \mathrm{z}$ values from 1000 to 10,000 , using a peptide standards set for calibration. Each mass spectrum was collected at 30 laser pulses at constant laser power and constant threshold value, in order to enhance the resolution.

\section{ACCESSION NUMBERS}

DNA sequences of $r s p E$ gene alleles of $N$. gonorrhoeae strains NG3, NG3.1, and NG3.2 were deposited into GenBank [accession numbers KF021591, KF021592, and KF021593, respectively].

\section{RESULTS AND DISCUSSION}

In this study we identified a molecular mechanism responsible for spectinomycin resistance in gonococci. As a part of unrelated experiment, $N$. gonorrhoeae strains with Spt-R phenotype were occasionally isolated. They were derived from clinical isolate e 03.04 belonged to Por1B3 serotype. Collected in 2004 it was identified as susceptible to penicillin, tetracycline, ciprofloxacin, and ceftriaxon. Spectinomycin MIC was defined as 32-64 mg/L, which corresponded to intermediate resistant (Spt-I) phenotype. When the susceptibility profile of this isolate was retested in 2008 two colonies emerged on the plate supplemented with $64 \mathrm{mg} / \mathrm{L}$ of spectinomycin. Each colony was seeded once again on plates with the same antibiotic concentration, and then on the plates with $128 \mathrm{mg} / \mathrm{L}$ of spectinomycin. It was a poor growth on plates with
$128 \mathrm{mg} / \mathrm{L}$ of spectinomycin, so two clones grown well under the $64 \mathrm{mg} / \mathrm{L}$ of spectinomycin were stored.

It should be noted that neither one of other $N$. gonorrhoeae isolates tested in this experiment nor the same e03.04 clinical isolate examined in repeats revealed any additional colonies survived under $64 \mathrm{mg} / \mathrm{L}$ of spectinomycin. Thus we have considered two occasionally isolated Spt-R clones as a small fraction of heterogeneous e03.04 clinical isolate. The collected strains were designated as NG3.1 and NG3.2. Gonococci derived from e03.04 isolate susceptible to spectinomycin treatment were also collected and stored as NG3 N. gonorrhoeae clinical strain.

Susceptibility testing data for clinical e03.04 isolate as well as for selected N. gonorrhoeae strains is presented in Table 1. In accordance with NG-MAST scheme all of them belonged to the same 5187 sequence type that supported the assumption of a common origin of the strains studied. Since, the only previously reported mechanism for Spt-R gonococci was C1192T mutation in 16S rRNA gene (Maness et al., 1974; Galimand et al., 2000), we have sequenced all four copies of 16S rRNA genes located in N. gonorrhoeae genomic DNA (for the number of rRNA genes copies see rrnDB database, http://ribosome.mmg.msu.edu/ rrndb/index.php). For each tested strain, all four copies of $16 \mathrm{~S}$ rRNA genes were found identical. Indeed, the 1192 position as well as a locus encoding for the 34 helix of $16 \mathrm{~S}$ rRNA, which forms the spectinomycin-binding site of ribosome (Carter et al., 2000; Wirmer and Westhof, 2006) possessed the wild-type sequence in NG3 strain as well as in NG3.1 and NG3.2 ones. So, we have proposed that other molecules located close by to the ribosomal spectinomycin-binding site could be involved in formation of Spt-R phenotype.

The crystal structure of the $30 \mathrm{~S}$ subunit of bacterial ribosome from E. coli in complex with spectinomycin (Carter et al., 2000) was taken into account and the ribosomal proteins S4, S5, and S8 were picked up for further examination due to their vicinity to a spectinomycin-binding site. Accordingly, $r p s D, r p s E$, and $r p s H$ genes were amplified and sequenced. No differences were found between $r p s D$, and $r p s H$ genes. However, both Spt-R $N$. gonorrhoeae strains (NG3.1 and NG3.2) carried the same A70C mutation in rpsE genes, leading to Thr-24 $\rightarrow$ Pro amino acid substitution at RPS5, which mapped to Ser-22 residue of RPS5 from E. coli (Figure 1).

The 19-33 loop of RPS5 is known to be RNA binding site, and is the most frequent zone for location of mutations related

1

ATCC49226 MAKHEIEERG DGLIEKMVAV NRVTKVVKGG RIMAFSALTV VGDGDGRIGM

FA1090 MAKHEIEERG DGLIEKMVAV NRVTKVVKGG RIMAFSALTV VGDGDGRIGM

NG3 MAKHEIEERG DGLIEKMVAV NRVTKVVKGG RIMAFSALTV VGDGDGRIGM

NG3.1 MAKHEIEERG DGLIEKMVAV NRVPKVVKGG RIMAFSALTV VGDGDGRIGM

NG3.2 MAKHEIEERG DGLIEKMVAV NRVPKVVKGG RIMAFSALTV VGDGDGRIGM

NM_MC58 MAKHEIEERG DGLIEKMVAV NRVTKVVKGG RIMAFSALTV VGDGDGRIGM

EC K12 MA-H-IEKQA GELQEKLIAV NRVSKTVKGG RIFSFTALTV VGDGNGRVGF

PM_1398 MA-N-IEKQA GELQEKLIAV NRVSKTVKGG RIMSFTALTV VGDGNGRVGF

FIGURE 1 | Multiple alignment of RPS5 sequences of NG3, NG3.1, and NG3.2 strains. The Thr-24 $\rightarrow$ Pro mutation is bolded. Deduced amino acid sequences of RPS5 of wild-type $N$. gonorrhoeae (ATCC49226, FA1090), N. meningitidis (NM_MC58), E. coli (EC_K12), and P. multocida (PM_1398) are also presented. Regions involved in formation of resistance to spectinomycin are underlined [according to Davies et al. (1998); Kehrenberg and Schwarz (2007)]. 
to spectinomycin resistance (Funatsu et al., 1972; Wirmer and Westhof, 2006; Kehrenberg and Schwarz, 2007). Mostly, RPS5 mutations associated with Spt-R phenotype occur simultaneously with 16 S rRNA changes. However, the isolated Ser-22 $\rightarrow$ Pro RPS5 mutation in resistant to spectinomycine E. coli strain was also described (Wilcox et al., 2001). Basing on this knowledge, we have suggested that the Thr-24 $\rightarrow$ Pro substitution found in RPS5 from NG3.1 and NG3.2 N. gonorrhoeae strains confer the Spt-R phenotype.

As an argument, that the single Thr- $24 \rightarrow$ Pro mutation in RPS5 can support a Spt-R phenotype alone, we performed a transformation of spectinomycin sensitive $N$. gonorrhoeae strains by the exogenic DNA fragment contained mutant rpsE gene. Furthermore, the experiments described below demonstrated a potential role of HGT in spread of spectinomycin resistance.

The $12931 \mathrm{bp}$ fragments of $N$. gonorrhoeae chromosomal DNA, which include whole rpsE gene and the nearest DNA uptake sequences (DUS12, $5^{\prime}$ atgccgtctgaa $3^{\prime}$ ) on their ends were amplified with primers indicated in Table 2. It was done using the NG3 (wild type) and NG3.1 (mutant) genomic DNAs as templates. The presence of DUS12 is known to be necessary for DNA recognition and uptake and therefore, mediates an increase in transformation efficiency (Duffin and Seifert, 2010).

Two different N. gonorrhoeae strains-NG7, and NG94, susceptible to spectinomycin were chosen as recipients. For each recipient, the spot transformation by purified amplified DNA fragment contained mutant (or wild) variant of $r p s E$ gene was carried out. The principal scheme of an experiment is represented in Figure 2. The transformation of recipients by a DNA fragment carried a wild variant of $r p s E$ gene was used as a negative control. Each experiment was repeated in triplicate.

As a result, $74.7 \pm 5.7$ and $15.6 \pm 2.5$ colonies emerged on GC agar plates supplemented with $64 \mathrm{mg} / \mathrm{L}$ of spectinomycin and derived from NG7 and NG94 bacterial cells transformed by mutant rpsE gene, respectively (Table 3). Bacterial cells transformed by DNA fragment carried wild type of $r p s E$ gene formed no colonies on spectinomycin supplemented GC agar plates. Transformation frequency calculated as the number of SPT ${ }^{\mathrm{r}} \mathrm{CFU}$ per total CFU was found $2.2 \pm 0.4 \times 10^{-5}$ and $1.7 \pm 0.2 \times 10^{-5}$ for NG7 and NG94 N. gonorrhoeae strains, respectively.

Each transformant survived after a re-cultivation on spectinomycin supplemented $(64 \mathrm{mg} / \mathrm{L})$ agar plates was tested by sequencing. All tested strains carried A70C mutation in rpsE gene identical to NG3.1 and NG3.2 N. gonorrhoeae strains and leading to Thr-24 $\rightarrow$ Pro amino acid substitution in RPS5. Otherwise, in accordance with NG MAST, they belonged to the same sequence types as the recipient strains from which they originated.

The spectinomycin MICs were measured for the transformants derived both from NG7 and NG94 N. gonorrhoeae recipient strains. In all cases, spectinomycin MICs increased fourfold (from $16-32 \mathrm{mg} / \mathrm{L}$ to $64-128 \mathrm{mg} / \mathrm{L}$ ) and became identical to the ones of NG3.1 and NG3.2 N. gonorrhoeae strains.

Described experiments verified that single Thr-24 $\rightarrow$ Pro amino acid substitution in RPS5 confers the Spc-R phenotype of N. gonorrhoeae strains.

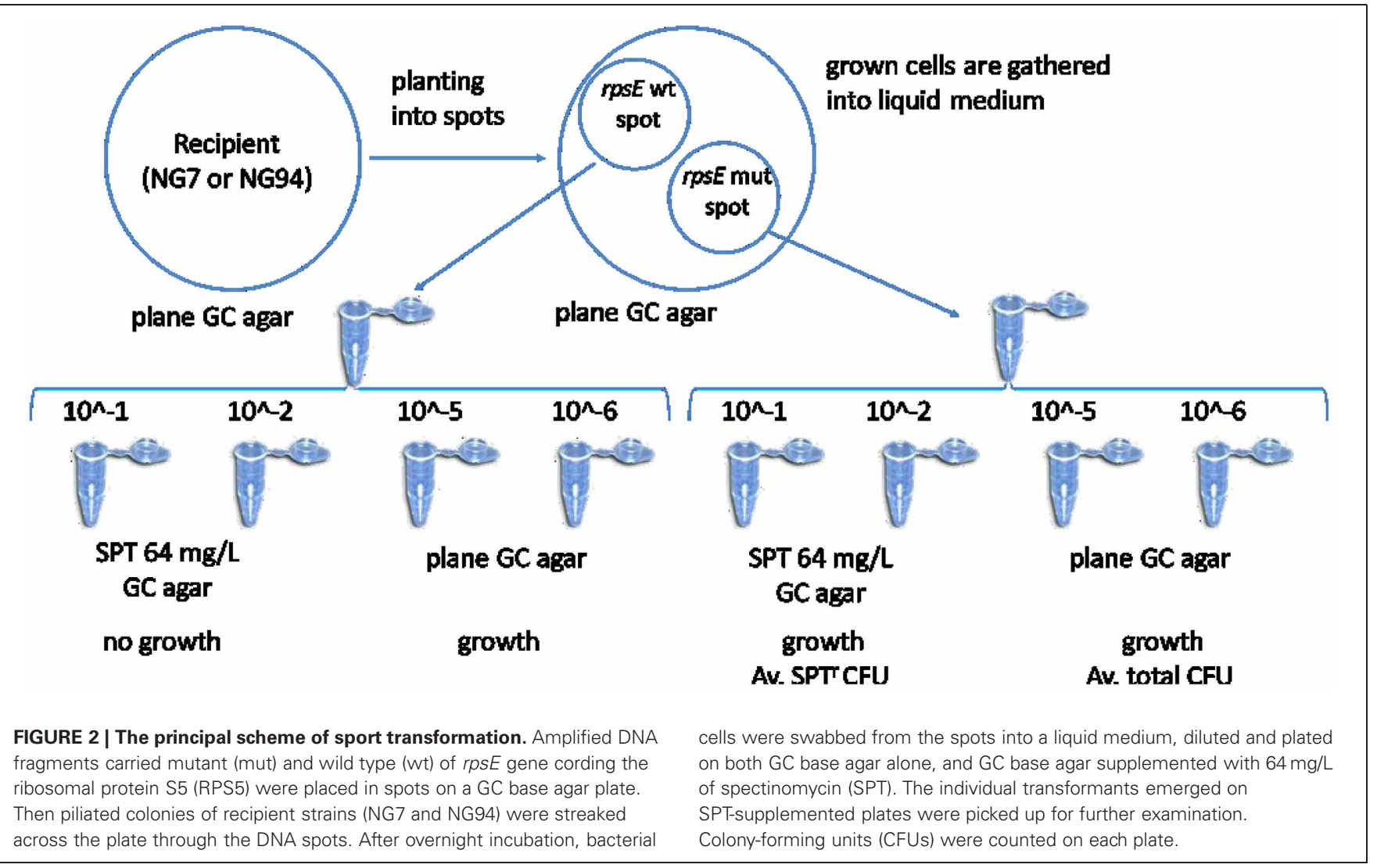


Table 3 | The calculated results of transformation experiments.

\begin{tabular}{|c|c|c|c|c|}
\hline Recipient & Av. SPT' CFUs & Av. SPT' CFU/ml & Av total CFU/ml & Transformation efficiency \\
\hline NG94 & $15.6 \pm 2.5$ & $0.8 \pm 0.2 \times 10^{4}$ & $4.7 \pm 0.2 \times 10^{8}$ & $1.7 \pm 0.2 \times 10^{-5}$ \\
\hline
\end{tabular}

An average data from three replicas is presented.

Furthermore, the transformation efficiency was found relatively high (ca. $10^{-5}$ ) and was not statistically different between both recipient strains. This finding supports the statement that the HGT through the natural transformation permits movement of mutant allele of $r p s E$ gene and increases the opportunity for the spread of spectinonycin resistance within gonococcal population.

The RPS5 mutation we verified here appeared to be the same that was described for $N$. gonorrhoeae WHO A strain (Unemo et al., 2013). This mutation results in low-level spectinomycin resistance in gonococci that agrees with our conclusion.

The main issue is that in this study, conducted independently the mutant allele of $r p s E$ gene was found in clinical $N$. gonorrhoeae strain isolated in Russia. This emphasizes that the described molecular mechanism of Spt-R phenotype formation is a universal one and spreads worldwide.

To extend the knowledge of frequency of RPS5 Thr-24 $\rightarrow$ Pro mutants the entire laboratory collection of $N$. gonorrhoeae genomic DNA ( $n=1131)$ acquired since 2002-2008 years was analyzed. The majority of them $(n=1113)$ were susceptible to spectinomycin, and the 18 strains revealed the Spt-I phenotype $(\mathrm{MICs}=32-64 \mathrm{mg} / \mathrm{L}$ ). Keeping in mind that NG3.1 and NG3.2 strains possessed Thr-24 $\rightarrow$ Pro mutation in RPS5 were found occasionally as a small fraction of a wild population, we did not exclude susceptible to spectinomycin gonococci from the examination.

No more mutant N. gonorrhoeae strains have been found. It seems the tested Thr-24 $\rightarrow$ Pro substitution in RPS5 is

\section{REFERENCES}

Allen, V. G., Farrell, D. J., Rebbapragada, A., Tan, J., Tijet, N., Perusini, S. J., et al. (2011). Molecular analysis of antimicrobial resistance mechanisms in Neisseria gonorrhoeae isolates from Ontario, Canada. Antimicrob. Agents Chemother. 55, 703-712. doi: 10.1128/AAC.00788-10

Bilgin, N., Richter, A. A., Ehrenberg, M., Dahlberg, A. E., and Kurland,C. G. (1990). Ribosomal RNA and protein mutants resistant to spectinomycin. EMBO J. 9, 735-739.

Binet, R., and Maurelli, A. T. (2005). Fitness cost due to mutations in the 16S rRNA associated with spectinomycin resistance in Chlamydia psittaci 6BC. Antimicrob. Agents. Chemother. 49, 4455-4464. doi: 10.1128/AAC.49.11.44554464.2005
Borovinskaya, M. A., Shoji, S., Holton, J. M., Fredrick, K., and Cate, J. H. D. (2007). A steric block in translation caused by the antibiotic spectinomycin. ACS Chem. Biol. 2, 545-552. doi: 10.1021/ cb700100n

Boslego, J. W., Tramont, E. C., Takafuji, E. T., Diniega, B. M., Mitchell, B. S., Small, J. W., et al. (1987). Effect of spectinomycin use on the prevalence of spectinomycin-resistant and of penicillinase-producing Neisseria gonorrhoeae. N. Engl. J. Med. 317, 272-278. doi: 10.1056/NEJM198707303170504

Brink, M. F., Brink, G., Verbeet, M. P., and de Boer, H. A. (1994). Spectinomycin interacts specifically with the residues G1064 and C1192 in $16 \mathrm{~S}$ rRNA, thereby potentially freezing this molecule into an inactive conformation. Nucleic Acids Res. 22, 325-331.

very rare among gonococci. This may reflect the uncommon use of spectinomycin in therapy of gonorrhea. On the other hand, we cannot deny that gonococci with mutation in ribosomal protein could be somehow defective in their survival and population spreading. Undoubtedly, fitness cost due to such mutation requires further careful investigation.

Nevertheless, our study is an additional evidence of the existing of clinical $N$. gonorrhoeae strains with moderate spectinomycin resistance due to isolated mutations in RPS5. It is very important in terms of the surveillance and the therapy of gonococcal infection. The extended knowledge of the potential mutations responsible for resistant phenotypes is essential in the development of new tests suitable in clinical setting, which aim to establish the correct antimicrobial therapy.

\section{ACKNOWLEDGMENTS}

We sincerely thank V. A. Karpov for the oligonucleotide primers synthesis; and M. M. Chukin for the assistance with the sequence instrumentation. We also declare that current investigation was first presented during the 18th International Pathogenic Neisseria Conference, Würzburg, Germany, 2012.

\section{TRANSPARENCY DECLARATION}

This research work received financial support from the Ministry of Health of the Russian Federation (Development Contract No 06/311 from 30/05/2008).

Carter, A. P., Clemons, W. M. Brodersen, D. E., MorganWarren, R. J., Wimberly, B. T., and Ramakrishnan, V. (2000). Functional insights from the structure of the $30 \mathrm{~S}$ ribosomal subunit and its interactions with antibiotics. Nature 407, 340-348. doi: $10.1038 / 35030019$

Clark, N. C., Olsvik, Ø., Swenson, J. M., Spiegel, C. A., and Tenover, F. C. (1999). Detection of a streptomycin/spectinomycin adenylyltransferase gene (aadA) in Enterococcus faecalis. Antimicrob. Agents Chemother. 43, 157-160.

CLSI document M100-S17. (2007). Performance standards for antimicrobialsusceptibilitytesting; seventeenth informational supplement. Clin. Lab. Stand. Inst. 27, 1-182.

Criswell, D., Tobiason, V. L., Lodmell, J. S., and Samuels, D. S. (2006).
Mutations conferring aminoglycoside and spectinomycin resistance in Borrelia burgdorferi. Antimicrob. Agents Chemother. 50, 445-452. doi: 10.1128/AAC.50.2.445-452.2006

Davies, C., Bussiere, D. E., Golden, B. L., Porter, S. J., Ramakrishnan,V., and White, S. W. (1998). Ribosomal proteins S5 and L6: high-resolution crystal structures and roles in protein synthesis and antibiotic resistance. J. Mol. Biol. 279, 873-888. doi: 10.1006/jmbi.1998.1780

Davies, J., and Davies, D. (2010). Origins and evolution of antibiotic resistance. Microbiol. Mol. Biol. Rev. 74, 417-433. doi: 10.1128/MMBR.00016-10

Dillard, J. P. (2011). "Genetic Manipulation of Neisseria gonorrhoeae," in Current Protocols in Microbiology, (Wiley Online Library). Available online at: wileyonlinelibrary.com 
Duffin, P. M., and Seifert, H. S. (2010). DNA uptake sequencemediated enhancement of transformation in Neisseria gonorrhoeae is strain dependent. J. Bacteriol. 192, 4436-4444. doi: 10.1128/JB.00442-10

Funatsu, G., Schiltz, E., and Wittmann, H. G. (1972). Ribosomal proteins. XXVII. Localization of the amino acid exchanges in protein S5 from two Escherichia coli mutants resistant to spectinomycin. Mol. Gen. Genet. 114, 106-111. doi: 10.1007/BF00332781

Galimand, M., Gerbaud, G., and Courvalin, P. (2000). Spectinomycin resistance in Neisseria spp. due to mutations in $16 \mathrm{~S}$ rRNA. Antimicrob. Agents Chemother. 44, 1365-1366. doi: 10.1128/AAC.44.5.1365-1366.2000

Heymans, R., Bruisten, S. M., Golparian, D., Unemo, M., de Vries, H. J., and van Dam, A.P. (2012). Clonally related Neisseria gonorrhoeae isolates with decreased susceptibility to the extended-spectrum cephalosporin cefotaxime in Amsterdam, the Netherlands. Antimicrob. Agents Chemother. 56, 1516-1522. doi: 10.1128/AAC.05481-11

Hollingshead, S., and Vapnek, D. (1985). Nucleotide sequence analysis of a gene encoding a streptomycin/spectinomycin adenyltransferase. Plasmid 13, $17-30$

Ilina, E. N., Vereshchagin, V. A., Borovskaya, A. D., Malakhova, M. V., Sidorenko, S. V., Al Khafaji, N. C., et al. (2008). Relation between genetic markers of drug resistance and susceptibility profile of clinical Neisseria gonorrhoeae strains. Antimicrob. Agents Chemother. 52, 2175-2182. doi: 10.1128/AAC.01420-07

Johanson, U., and Hughes, D. (1995). A new mutation in 16S rRNA of Escherichia coli conferring spectinomycin resistance. Nucleic Acids Res. 23, 464-466. doi: 10.1093/nar/23.3.464

Kehrenberg, C., Catry, B., Haesebrouck, F., de Kruif, A. and Schwarz, S. (2005). Novel Spectinomycin/Streptomycin Resistance Gene, aadA14, from Pasteurella multocida, Antimicrob. Agents Chemother. 49, 3046-3049. doi: 10.1128/AAC.49.7.3046-3049. 2005

Kehrenberg, C., and Schwarz, S. (2007). Mutations in 16S rRNA and ribosomal protein S5 associated with high-level spectinomycin resistance in Pasteurella multocida. Antimicrob. Agents Chemother. 51, 2244-2246. doi: 10.1128/AAC. 00229-07

Koomey, M. (1998). Competence for natural transformation in Neisseria gonorrhoeae: a model system for studies of horizontal gene transfer. APMIS Suppl. 84, 56-61.

Kubanova, A., Frigo, N., Kubanov, A., Sidorenko, S., Lesnaya, I., Polevshikova, S., et al. (2010). The Russian gonococcal antimicrobial susceptibility programme (RU-GASP)-national resistance prevalence in 2007 and 2008, and trends during 2005-2008. Euro Surveill. 15, pii: 19533.

LeBlanc, D. J., Lee, L. N., and Inamine, J. M. (1991). Cloning and nucleotide base sequence analysis of a spectinomycin adenyltransferase AAD (9) determinant from Enterococcus faecalis. Antimicrob. Agents Chemother. 35, 1804-1810. doi: 10.1128/AAC.35.9.1804

Maness, M. J., Foster, G. C., and Sparling, P. F. (1974). Ribosomal resistance to streptomycin and spectinomycin in Neisseria gonorrhoeae. J. Bacteriol. 120, 1293-1299.

Martin, I. M. C., Ison, C. A., Aanensen, D. M., Fenton, K. A., and Spratt,
B. G. (2004). Rapid sequencebased identification of gonococcal transmission clusters in a large metropolitan area. J. Infect. Dis. 189, 1497-1505. doi: 10.1086/383047

Shaw, K. J., Rather, P. N., Hare, R. S., and Miller, G. H. (1993). Molecular genetics of aminoglycoside resistance genes and familial relationships of the aminoglycosidemodifying enzymes. Microbiol. Rev. $57,138-163$.

Sigmund, C. D., Ettayebi, M., an Morgan, E. A. (1984). Antibiotic resistance mutations in $16 \mathrm{~S}$ and 235 ribosomal RNA genes of Escherichia coli. Nucleic Acids Res. 12, 4653-4663. doi: 10.1093/nar/12.11.4653

Unemo, M., Golparian, D., Nicholas, R., Ohnishi, M., Gallay, A., and Sednaoui, P. (2012). High-level cefixime- and ceftriaxone-resistant Neisseria gonorrhoeae in France: novel penA mosaic allele in a successful international clone causes treatment failure. Antimicrob. Agents Chemother. 56, 1273-1280. doi: 10.1128/AAC.05760-11

Unemo, M., Golparian, D., Skogen, V. Olsen, A. O., Moi, H., Syversen, G., et al. (2013). Neisseria gonorrhoeae strain with high-level resistance to spectinomycin due to a novel resistance mechanism (mutated ribosomal protein S5) verified in Norway. Antimicrob. Agents Chemother. 57, 1057-1061. doi: 10.1128/AAC.01775-12

Wang, S. A., Lee, M. V., O'Connor, N., Iverson, C. J., Ohye, R. G., Whiticar, P. M., et al. (2003). Multidrug-resistant $N$. gonorrhoeae with decreased susceptibility to cefixime-Hawaii, 2001. Clin. Infect. Dis. 15, 849-852. doi: $10.1086 / 377500$

Wilcox, S. K., Cavey, G. S., and Pearson, J. D. (2001). Single ribosomal protein mutations in antibiotic-resistant bacteria analyzed by mass spectrometry. Antimicrob. Agents Chemother. 45, 3046-3055. doi: 10.1128/ AAC.45.11.3046-3055.2001

Wirmer, J., and Westhof, E. (2006). Molecular contacts between antibiotics and the $30 \mathrm{~S}$ ribosomal particle. Methods Enzymol. 415, 180-202. doi: 10.1016/S0076-6879 (06) 15012-0

Yamada, D., Tipper, D., and Davies, J. (1968). Enzymatic inactivation of streptomycin by R-factor resistant Escherichia coli. Nature 219, 288-291. doi: 10.1038/ 219288a0

Conflict of Interest Statement: The authors declare that the research was conducted in the absence of any commercial or financial relationships that could be construed as a potential conflict of interest.

Received: 29 March 2013; accepted: 19 June 2013; published online: 10 July 2013.

Citation: Ilina EN, Malakhova $M V$, Bodoev IN, Oparina NY, Filimonova $A V$ and Govorun VM (2013) Mutation in ribosomal protein $S 5$ leads to spectinomycin resistance in Neisseria gonorrhoeae. Front. Microbiol. 4:186. doi 10.3389/fmicb.2013.00186

This article was submitted to Frontiers in Antimicrobials, Resistance and Chemotherapy, a specialty of Frontiers in Microbiology.

Copyright (c) 2013 Ilina, Malakhova, Bodoev, Oparina, Filimonova and Govorun. This is an open-access article distributed under the terms of the Creative Commons Attribution License which permits use, distribution and reproduction in other forums, provided the original authors and source are credited and subject to any copyright notices concerning any third-party graphics etc. 